\title{
A Framework to select the most suitable Delay Analysis Technique for Building Construction through a consideration of Utility Factors
}

\author{
Perera B.A.K.S \\ Department of Building Economics, University of Moratuwa, Sri Lanka \\ Sudeha H.M.C.K \\ Amana Contracting and Steel Buildings LLC, Dubai \\ pererabaks@gmail.com,best.of.sudeha@gmail.com
}

\begin{abstract}
Delay results in disputes, which in many cases retard the progress of a project. Due to its criticality, a wide range of Delay Analysis Techniques (DAT) has been developed by various analysts over the years to address the issue. With the passage of time, analysts have identified the inherent properties or factors of each of these methodologies according to which they can be grouped into filter and utility factors. However, in the Sri Lankan construction industry, solutions to resolving and managing construction delays remain at an elementary level with most analysts opting for an ad-hoc selection of delay analysis techniques rather than being governed by considerations of suitability. Recognizing the importance of utility factors in construction delays, this study takes into consideration utility factors in the development of a framework that would aid in the selection of the most suitable DAT for the purpose of analyzing delays in the Sri Lankan building construction industry. A preliminary questionnaire survey was initially conducted, which sought to identify current delay analysis procedures, the use of DATs in the Sri Lankan building construction industry, and factors affecting the selection of DAT. The study was further expanded through a secondary questionnaire survey in order to select the most suitable delay analysis technique through a consideration of utility factors. The framework developed directs analysts to select the most suitable DAT via a consideration of utility factors. The proposed framework will lead to a reduction in the error margin in delay analysis while aiding the increase in accuracy of delay analysis.
\end{abstract}

\section{Introduction}

Delay remains one of the most common claim types in the construction industry. Since claims could be very complex and difficult to resolve, they have the potential to create havoc in the construction industry. It is therefore necessary to adopt delay analysis methods to resolve claims. However, delay analysis may be influenced by the method or technique selected. Therefore, selecting the most appropriate technique is of paramount importance for which the analyst has to consider the factors affecting the selection of the Delay Analysis Technique (DAT). Gunarathne (2012) divides all factors affecting the selection of the suitable DAT into "filter" and "utility" factors. The author further specified that utility factors represented the required level of utility of the factors to be considered by parties when selecting a single DAT against the inheriting properties and that filter factors are the ones that consist of 0.5 probability to each "yes" and "no" response of the relevant context properties. He went on to mention that in selecting the most appropriate DAT, a primary screening can be done using filter factors. After filtering out certain techniques from the filter factors, the selection of the most appropriate method depends on the weighting of DATs and the utility factors. Therefore, taking into consideration utility factors for the selection of the most appropriate DAT is a more advanced method than selecting from filter factors. Simultaneously, the systematic and accurate consideration of utility factors will increase 
the accuracy level of the delay analysis while decreasing the potential error margin.

At present, in the Sri Lankan construction industry, most delay analysts use one or two DAT to analyze each and every scenario rather than without taking into consideration the suitability of all available techniques. The absence of a proper system to select the most suitable DAT for a particular scenario can be identified as the main reason for this. However, developing a suitable system will lead to an increase in the accuracy of the delay analysis process. The aim of this paper is to provide a framework for selecting the most suitable DAT for the particular scenario under consideration taking into account the utility factors. The following objectives have been established to achieve this broader aim: identification of construction delays and delay types; identification of DATs used in the Sri Lankan building construction industry; identification of factors affecting the selection of DAT; and, finally, identification of the utility factors that need to be considered in the selection of the DAT

\section{Relevance of the Research}

In the Sri Lankan construction industry, only a few professionals have been involved in resolving and managing construction delays (Institute of Dispute Management Professionals [IDMP], 2013). What is more, these professionals tend to go for ad-hoc selection of DAT rather than giving priority to consideration of the suitability of the technique for a given scenario (Gunarathne, 2012), the consequence of which would be an increase in the error margin of the estimate and a decrease in the level of accuracy of the final outcome while also giving an unfair decision to the client, contractor or another party among those involved (Braimah \& Ndekugri, 2008). Therefore, the factors which affect the selection of DAT have to be taken into consideration prior to the selection of the DAT in order to give a fair decision in terms of all the parties involved. As mentioned earlier, in order to increase the accuracy and to decrease the level of error margin, more priority has to be given to the utility factors. As mentioned by Gunarathne (2012) in his research, though this area is of the utmost importance in analyzing delay, it remains under-researched. The present paper aims to develop a framework to select the most suitable delay analysis technique for the Sri Lankan construction industry taking into consideration the utility factors.

\section{Research Methodology}

Three types of methods were used in the study to collect data, viz., preliminary interviews and a questionnaire in two parts. Four preliminary interviews were carried out with experts having more than 25 years of working experience in the construction industry in order to gather information which cannot be gleaned from a literature survey such as the identification of delay types and DATs used in the Sri Lankan context, to check the applicability of utility factors that were identified in the literature review, to identify new factors according to the context, and to clarify and gather more details about the identified utility factors.

Of the two-part questionnaire, part I was based on the Likert scale, which focused on identifying the various DATs used in the Sri Lankan construction industry and identifying the various utility factors which affected the selection of the DAT and the impact of each utility factor on selecting a DAT. Part II of the questionnaire was based on the Analytical Hierarchical Process (AHP) in order to develop a conceptual framework to select the most suitable DAT for a particular scenario.

The findings from the survey would enable the researchers to adapt the information from the literature review to suit the Sri Lankan context and to develop a framework for the particular scenario under consideration. While part I of the questionnaire survey was carried out with 23experts in the construction industry, part II of the questionnaire survey was carried out with 30 experts in the construction industry.

The data obtained through part I of the questionnaire survey was analyzed using the Relative Important Index (RII). Many researches (El-Sayegh, 2008; Jeyamathan \& Rameezdeen, 2006; Sumithiran, 2009) have identified RII as a data analysis technique for ranking factors for the purpose of identifying 
the most significant factors. The study utilized the Analytical Hierarchy Process (AHP) tool because it permits a hierarchical structure of the criteria, which enables users to focus better on specific criteria and sub-criteria when allocating the weights. It is also both easier and more accurate to express one's opinion on only two alternatives than simultaneously on all the alternatives. Since, in this research, it is necessary to compare one utility factor with another and to prioritize each factor relative to the other utility factors, the AHP tool can be used as a more suitable data analysis method for this research. Lam \& Zhao (1998), Cheng \& Li (2001) and Dey (2002) are the other researchers who have conducted similar researches based on the AHP method for a sample size below thirty.

\section{Literature Synthesis}

\subsection{Construction Delays}

The time-period stipulated for the completion of a particular construction activity is usually an important consideration for both the client and the main contractor (Kraiem \& Diekmann, 1987). Researchers have, however, pointed that it is typical for construction projects to face delay due to a variety of factors. But delays in construction can result in a number of changes in a project such as late completion, lost productivity, acceleration, increased costs, and contract termination (Semple, Harman, \& Jergeas, 1994). When construction delays occur, it is necessary to ascertain the liabilities of the contracting parties and to direct the appropriate amount of resources for the purpose of recovering the schedule (Lyons \& Skitmore, 2004).

According to Enshassi, Al-Najjar and Kumaraswamy (2009), there are, in general, three types of construction delays, namely, inexcusable delays, excusable delays and concurrent delays. Excusable delays can be further divided into compensable and noncompensable delays (Menesi, 2007). Alkass, Mazerolle, and Harris (1996) pointed out that if there is a delay or delays for which neither the client nor the contractor is deemed responsible, such delays are called "Excusable non-compensable delays". For this kind of delay, only a time extension can be warranted.
Delays which are caused due to the client's actions or inactions are called "Excusable compensable delays". In such circumstances, the contractor is entitled to a time extension as well as monetary compensation (Braimah, 2008). However, in almost all instances, even where the project is relatively simple, the analysis of delay is difficult and complicated because of the large number of individual activities that have to be dealt with (Shi, Cheung, \& Arditi, 2001). In order to manage that complexity in processing construction delays, the many literature sources available, in the form of journals, articles and books (Yang, Kao, \& Lee, 2006), introduce a numbers of techniques.

\subsection{Delay Analysis Techniques (DATs)}

The delay and disruption protocol of the Society of Construction Law (2002) identified five commonly used delay analysis techniques, which can be identified as impacted-as-planned method, time-impact analysis method, collapsed as-built or 'but-for' analysis method, the snapshot/windows/time slice analysis method and as-planned versus as-built method. Further, Yang et al. (2006) identified as-planned versus as-built technique, impacted-as-planned technique, 'but-for' technique, and time-impact technique as some of the special and popular techniques used in the construction industry to analyze construction delays.

In addition to the above-mentioned DAT, other delay analysis techniques have been proposed in the available literature sources while alternative names have been used by different authors for the same method (Hegazy $\&$ Zhang, 2005). For instance, Yang et al. (2006) used the name "windows technique" for the DAT that Alkass et al. (1995) called the "snapshot technique." Similarly, the DAT that most researchers call "as-planned vs.asbuilt", some researchers call "adjusted as-built Critical Path Method (CPM)while "total time and impacted as-built CPM" is the term that others use for the same DAT. Table 1 gives the various delay analysis methods proposed by the different authors. It also shows that the concept of "as-planned $v s$ as-built" DAT is captioned differently. 
Given below are the techniques that more than ten authors have identified among the most popular and special DAT (see Table 1), which leads to the reasonable conclusion that they are the most common and popular delay analysis techniques used in the construction industry:

- Global Impact (GI) Technique

- As-Planned vs. As-Built (AP vs. AB) Technique

- Impacted As-Planned (IAP) Technique

- Time Impact Analysis (TIA) Technique

- Collapsed As-Built (CAB) Technique

The present research used the above five techniques to conceptualize and propose the most suitable framework for the Sri Lankan construction industry.

As seen from the above, various authors have proposed several delay analysis methods (Refer Table 1). Even though there are a number of methods, no one method can be used universally over another in all situations (Pinnell, 1998). In the international construction industry, the selection of the proper analysis method depends upon a variety of factors including availability of information, time of analysis, capability, and the time, cost and effort allocated to the analysis rather than ad-hoc selection (Arditi \& Pattanakitchamroon, 2006). These factors which had several sub-factors and the availability of information factor contained two main sub-headings such as the type of schedule that included as-planned schedule, as-built schedule, updated schedules, adjusted schedules, fragments and type of information but no CPM and no CPM but progress record, CPM approved or not updated, CPM approved or updated. The time of analysis included subfactors such as foresight, real time, and hindsight during the performance period and after project completion. Likewise, the other three factors identified by Arditi \& Pattanakitchamroon (2006) contained unique sub-factors for each factor.

On the other hand, according to the SCL delay and disruption protocols (2002), there are four main criteria to be considered when selecting which delay analysis methodology should be used as follows:

- What does the contract require?
- Which approach is appropriate, correct and sustainable?

- Does a lack of information restrain the use of any of the approaches?

- Do time or cost constraints eliminate certain options?

In comparison with the above two selection criteria, the criteria of Arditi and Pattanakitchamroon (2006) are only for four delay analysis techniques such as As-planned vs. as-built analysis, Impact as-planned analysis, Collapsed as-built analysis and Time-impact analysis. However, the selection criteria of the SCL delay and disruption protocol (2002) can be used for the selection of any kind of method for a particular scenario. Therefore, the selection criteria of SCL delay and disruption protocol (2002) is the most suitable criteria for use.

The international construction industry, with its developed construction culture, always follows systematic ways to select the most suitable DAT for a particular scenario. Further, the international construction industry gives priority to factors affecting the selection of the DAT prior to its selection. Braimah and Ndekugri (2008) introduced a well-developed system where factors were sorted into six groups that influence the selection of DAT for the UK construction industry. Further, they pointed out that these six, well-developed group factors include project characteristics, requirements of the contract, characteristics of the baseline programme, cost proportionality, timing of analysis, and record availability. Under these six groups, eighteen sub-factors which directly or indirectly affect the selection of the delay analysis methodology for a particular scenario have been identified by them. 


\begin{tabular}{|c|c|c|c|c|c|c|c|c|c|c|c|c|c|c|c|}
\hline $\begin{array}{l}\text { Delay Analysis } \\
\text { Technique }\end{array}$ & 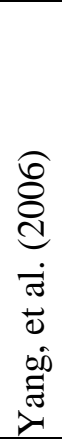 & 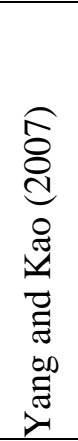 & $\begin{array}{l}\widehat{\approx} \\
\stackrel{\infty}{\Xi} \\
\stackrel{\Xi}{\Xi}\end{array}$ & 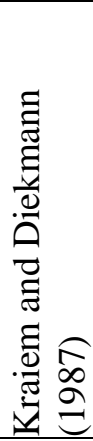 & $\begin{array}{l}\widehat{\curvearrowright} \\
\stackrel{\infty}{\Xi} \\
\mathscr{\Xi} \\
\tilde{\Xi} \\
\widetilde{\Xi}\end{array}$ & 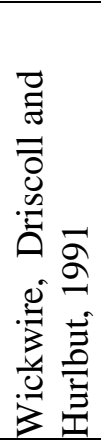 & 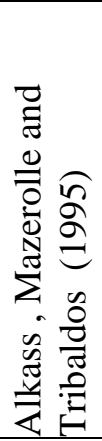 & 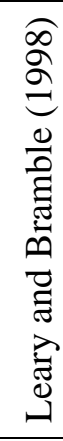 & 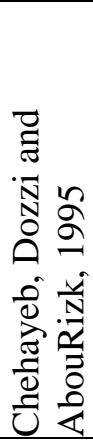 & 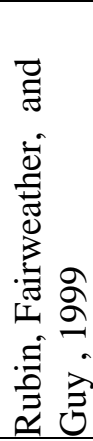 & $\begin{array}{l}\stackrel{\infty}{\circ} \\
\stackrel{\sigma}{\Xi} \\
\overline{\overline{0}} \\
\vdots \\
0\end{array}$ & 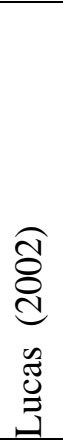 & 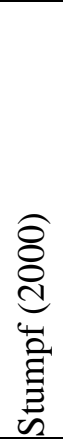 & 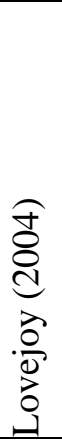 & 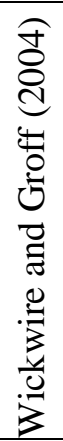 \\
\hline Global Impact Technique & $\sqrt{ }$ & $\sqrt{ }$ & $\sqrt{ }$ & $\sqrt{ }$ & $\sqrt{ }$ & $\sqrt{ }$ & $\sqrt{ }$ & $\sqrt{ }$ & $\sqrt{ }$ & & $\sqrt{ }$ & & & & \\
\hline Net Impact Technique & $\sqrt{ }$ & & & $\sqrt{ }$ & & & & & $\sqrt{ }$ & & & & & & \\
\hline Adjusted As-built CPM Technique & $\sqrt{ }$ & $\sqrt{ }$ & & & & & $\sqrt{ }$ & $\sqrt{ }$ & & & & & & & \\
\hline As-planned vs.As-built & & & $\sqrt{ }$ & $\sqrt{ }$ & & $\sqrt{ }$ & & & $\sqrt{ }$ & & & $\sqrt{ }$ & $\sqrt{ }$ & $\sqrt{ }$ & \\
\hline Total Time & & . & & & & & & & & & & & & & $\sqrt{ }$ \\
\hline Impacted As-built CPM & & 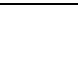 & & & $\sqrt{ }$ & & & & & & $\sqrt{ }$ & & & & \\
\hline As Planned But for & & . & & & & & $\sqrt{ }$ & & & & $\sqrt{ }$ & & & & \\
\hline Impacted As planned & & $\sqrt{ }$ & $\sqrt{ }$ & $\sqrt{ }$ & $\sqrt{ }$ & $\sqrt{ }$ & & & $\sqrt{ }$ & $\sqrt{ }$ & $\sqrt{ }$ & $\sqrt{ }$ & & & $\sqrt{ }$ \\
\hline Collapsed As-built & $\sqrt{ }$ & $\sqrt{ }$ & $\sqrt{ }$ & $\sqrt{ }$ & $\sqrt{ }$ & $\sqrt{ }$ & $\sqrt{ }$ & $\sqrt{ }$ & & & $\sqrt{ }$ & & & $\sqrt{ }$ & $\sqrt{ }$ \\
\hline As-planned Expanded Technique & $\sqrt{ }$ & $\sqrt{ }$ & & & & & & & & & & & & & \\
\hline Collapsed But-for Technique & $\sqrt{ }$ & & & & & & $\sqrt{ }$ & $\sqrt{ }$ & $\sqrt{ }$ & & & & & & \\
\hline Snapshot Technique & & & $\sqrt{ }$ & $\sqrt{ }$ & $\sqrt{ }$ & $\sqrt{ }$ & $\sqrt{ }$ & $\sqrt{ }$ & $\sqrt{ }$ & & & & & & \\
\hline Windows Technique & $\sqrt{ }$ & $\sqrt{ }$ & & & & & & & & & & & & $\sqrt{ }$ & \\
\hline Time Impact Technique & $\sqrt{ }$ & $\sqrt{ }$ & $\sqrt{ }$ & $\sqrt{ }$ & $\sqrt{ }$ & $\sqrt{ }$ & $\sqrt{ }$ & $\sqrt{ }$ & $\sqrt{ }$ & & & & & & \\
\hline Isolated Delay Type Technique & $\sqrt{ }$ & & & & & & & $\sqrt{ }$ & & & & & & & \\
\hline Apportionment Delay & & & & & $\sqrt{ }$ & & $\sqrt{ }$ & & $\sqrt{ }$ & & & & & & \\
\hline S- Curve & & & & & & & & & & $\sqrt{ }$ & & & & & \\
\hline
\end{tabular}

Table 1: Various DATs in Literature 
4.3 Factors Affecting the Selection of Delay Analysis Techniques

\subsubsection{Identification of Factors}

The selection of the most appropriate technique is important to all parties concerned (Braimah \& Ndekugri, 2008). The protocol of the Society of Construction Law (SCL) (2002) has identified a number of pre-requisites that analysts should focus on in order to identify the most suitable DAT for the respective scenario. As shown by Ramanathan et al (2012), the main group factors for the selection of DAT are the time of analysis and capabilities of the method, the relevant conditions of the contract, the nature of the causative events, the value of the dispute, the programme information available and the programmer's skill level and familiarity with the project characteristics, and the characteristics of the baseline programme, which are followed by several sub-factors. Similarly, Arditi and Pattanakitchamroon (2006) and Braimah and Ndekugri (2008) also introduced six welldeveloped group factors which included eighteen sub-factors that influence the selection of DAT in the case of the construction industry of the United Kingdom.

Since the perspectives of Sri Lankan construction industry professionals regarding factors causing construction delays such as poor documentation, lack of professionals in the industry, lack of supervision, construction methodology, value of the money, etc. can be different from those of UK construction industry professionals, given below are the twenty factors that must be taken into consideration in implementing an accurate delay-assessing method for the Sri Lankan construction industry (See Table 2). These factors were identified through part I of the questionnaire survey carried out among professionals in the Sri Lankan industry. Furthermore, in order to get a better insight into the research topic, factors previously elicited through the literature survey were brought to the attention of the industry professionals for the purpose of identifying the most suitable factors for the Sri Lankan context.

\begin{tabular}{|c|c|c|c|}
\hline \multicolumn{2}{|c|}{ Factors Identified } & \multirow{2}{*}{$\begin{array}{l}\text { Utility } \\
\text { Factor } \\
\frac{\sqrt{ }}{}\end{array}$} & \multirow{2}{*}{$\begin{array}{l}\text { Filter } \\
\text { Factor }\end{array}$} \\
\hline $\mathrm{U}_{1}$ & Record Availability & & \\
\hline $\mathrm{U}_{2}$ & $\begin{array}{l}\text { Nature of Baseline } \\
\text { Programme }\end{array}$ & $\sqrt{ }$ & \\
\hline $\mathrm{U}_{3}$ & $\begin{array}{l}\text { The Other Party to the } \\
\text { Claim }\end{array}$ & $\sqrt{ }$ & \\
\hline $\mathrm{U}_{4}$ & Applicable Legislation & $\sqrt{ }$ & \\
\hline $\mathrm{U}_{5}$ & The Form of Contract & $\sqrt{ }$ & \\
\hline $\mathrm{U}_{6}$ & $\begin{array}{l}\text { Skills of the Analyst } \\
\text { and his/her Familiarity } \\
\text { with the Project }\end{array}$ & $\sqrt{ }$ & \\
\hline $\mathrm{U}_{7}$ & Size of the Project & $\sqrt{ }$ & \\
\hline $\mathrm{U}_{8}$ & Duration of the Project & $\sqrt{ }$ & \\
\hline $\mathrm{U}_{9}$ & $\begin{array}{l}\text { Complexity of the } \\
\text { Project }\end{array}$ & $\sqrt{ }$ & \\
\hline $\mathrm{U}_{10}$ & The Amount in Dispute & $\sqrt{ }$ & \\
\hline $\mathrm{U}_{11}$ & $\begin{array}{l}\text { Dispute Resolution } \\
\text { Forum }\end{array}$ & $\sqrt{ }$ & \\
\hline $\mathrm{U}_{12}$ & $\begin{array}{l}\text { Time Availability for } \\
\text { Delay Analysis }\end{array}$ & $\sqrt{ }$ & \\
\hline $\mathrm{U}_{13}$ & $\begin{array}{l}\text { Cost of Using the } \\
\text { Technique }\end{array}$ & $\sqrt{ }$ & \\
\hline $\mathrm{F}_{1}$ & $\begin{array}{l}\text { Nature of the Delaying } \\
\text { Events }\end{array}$ & & $\sqrt{ }$ \\
\hline $\mathrm{F}_{2}$ & $\begin{array}{l}\text { Baseline Programme } \\
\text { Availability }\end{array}$ & & $\sqrt{ }$ \\
\hline $\mathrm{F}_{3}$ & $\begin{array}{l}\text { The Number of } \\
\text { Delaying Events }\end{array}$ & & $\sqrt{ }$ \\
\hline $\mathrm{F}_{4}$ & $\begin{array}{l}\text { Updated Programme } \\
\text { Availability }\end{array}$ & & $\sqrt{ }$ \\
\hline $\mathrm{F}_{5}$ & Time of the Delay & & $\sqrt{ }$ \\
\hline $\mathrm{F}_{6}$ & $\begin{array}{l}\text { Reason for the Delay } \\
\text { Analysis }\end{array}$ & & $\sqrt{ }$ \\
\hline $\mathrm{F}_{7}$ & $\begin{array}{l}\text { Nature of the Proof } \\
\text { Required }\end{array}$ & & $\sqrt{ }$ \\
\hline
\end{tabular}

Table 2: Factors Affecting the Selection of DAT

\subsubsection{Categorization of Factors}

According to Gunarathne, all the factors, including the sub-factors affecting the selection of suitable DAT, can be divided into "filter factors and utility factors" (2012). Furthermore, he illustrated that utility factors represent the required level of utility of the factors to be considered by the parties when selecting a single DAT against the inheriting properties. Gunarathne (2012) further mentioned that the primary screening to select the most appropriate DAT can be done by using filter factors. After filtering out certain techniques from the filter factors, the selection of the most appropriate method depends on the weighting of DATs and the utility factors. Consideration of utility factors for the selection of DAT is therefore a more advanced method than selecting filter 
factors. Simultaneously, the systematic and accurate consideration of the utility factors will increase the accuracy level of the delay analysis while decreasing the potential error margin.

Of the factors mentioned above, the designation of some as utility factors was done by the four experts involved in the survey. The remaining factors were designated as filter factors which consist of 0.5 probability to each of the "yes" and "no" responses in terms of the relevant context properties.

While the utility factors would vary according to the delay analyst's approach, the filters would remain unchanged. Table 2 sums up and categorizes the factors identified above.

\section{Research Findings}

\subsection{Identifying the Use of Delay Analysis Techniques in the Sri Lankan Building Construction Industry}

While various delay analysis techniques have been proposed in the literature, alternative names, as mentioned above, have been used by different authors for the same method (Hegazy \& Zhang, 2005). The results of part I of the questionnaire survey conducted among experts in the Sri Lankan construction industry show that Impacted As-Planned, Time Impact Analysis, Collapsed As-Built, As-Planned vs. AsBuilt, and Global Impact Technique are the ones which are currently used in the Sri Lankan building construction industry. Table 3 reports the DAT that have been identified. In addition to the DAT identified in the literature (see Table 3), respondents have also identified two additional delay analysis methods used in the Sri Lankan construction industry (see Table 3).

\begin{tabular}{|l|c|c|}
\hline $\begin{array}{c}\text { Delay Analysis } \\
\text { Techniques Used in the } \\
\text { Sri Lankan Building } \\
\text { Construction Industry }\end{array}$ & $\begin{array}{c}\text { No of } \\
\text { Respo } \\
\text { ndents }\end{array}$ & $\begin{array}{c}\text { Order } \\
\text { of } \\
\text { Usage }\end{array}$ \\
\hline Time Impact Analysis & 23 & 1 \\
\hline As Planned vs As Built & 23 & 1 \\
\hline Impacted As Planned & 19 & 3 \\
\hline Global Impact Technique & 13 & 4 \\
\hline Collapsed As-Built & 10 & 5 \\
\hline By Using Schedule & 2 & \\
CTabulate Format & \\
\hline By Using Letters & \\
\hline
\end{tabular}

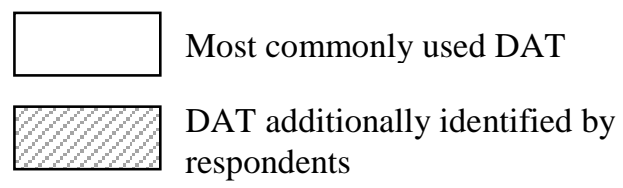

Table 3: DAT Used in the Sri Lankan Building Construction Industry

\subsection{Factors Affecting the Selection of Delay Analysis Techniques in the Sri Lankan Building Construction Industry}

According to Braimah, factors affecting the selection of DAT vary from country to country and depend on the nature of the construction industry (2008). He has further ranked the factors affecting the selection of DAT for the United Kingdom. A comparison of the ranking of those factors in the Sri Lankan construction industry with that for UK offered by Braimah reveals significant differences between the two rankings (see Table 4). However, in both cases, "Record Availability" is the most important factor to be considered when selecting DAT for a particular scenario. Furthermore, the respondents identified factors such as having an accurate baseline programme, updated programme, and skill of the analyst as the important factors to be considered when selecting DAT for the local industry.

During part I of the questionnaire survey, the respondents were asked to identify the factors affecting the selection of DAT for the Sri Lankan building construction industry, the results of which are presented in Table 4. Figure 1 presents a comparison between the findings of Braimah (2008) for United Kingdom and the findings of part I of our questionnaire survey for Sri Lanka. In addition to the factors identified by Braimah 
(2008), the survey identified five additional factors which are given in Table 4 with shading.

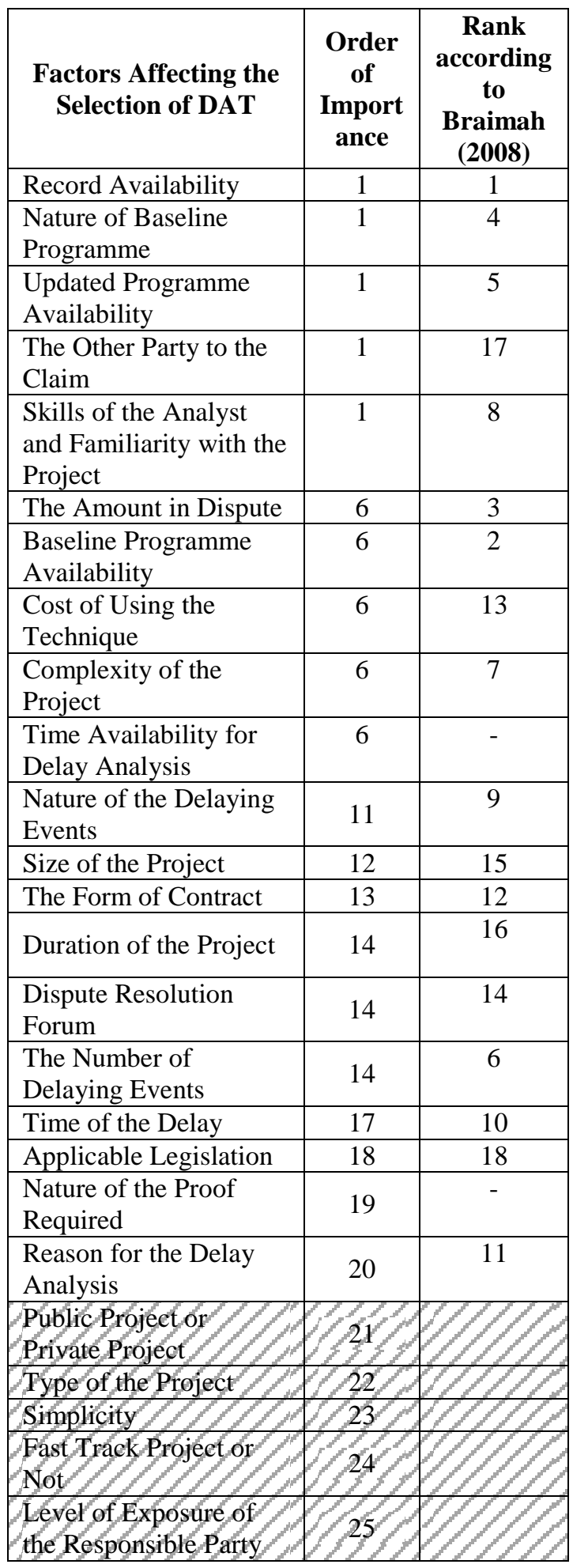

Table 4: Factors Affecting the Selection of DAT
The comparison between the findings of Braimah (2008) for the United Kingdom and the findings from part I of the questionnaire survey for the Sri Lankan construction industry reveals that, in both, the "Record Availability" factor occupies the number 1 slot as the most important factor to be considered when selecting DAT. Similarly, in both scenarios, the least importance was placed on the "Applicable Legislation" factor when selecting DAT. Apart from these two factors, the order of importance of the other factors is different in comparison with what is available in the literature synthesis. As mentioned earlier, the main reason for this difference is the fact that the order of importance of these factors varies from country to country.

The 25 factors which were identified in the analysis of part I of the questionnaire survey need to be considered when selecting a suitable DAT for a particular scenario in the local construction industry. 


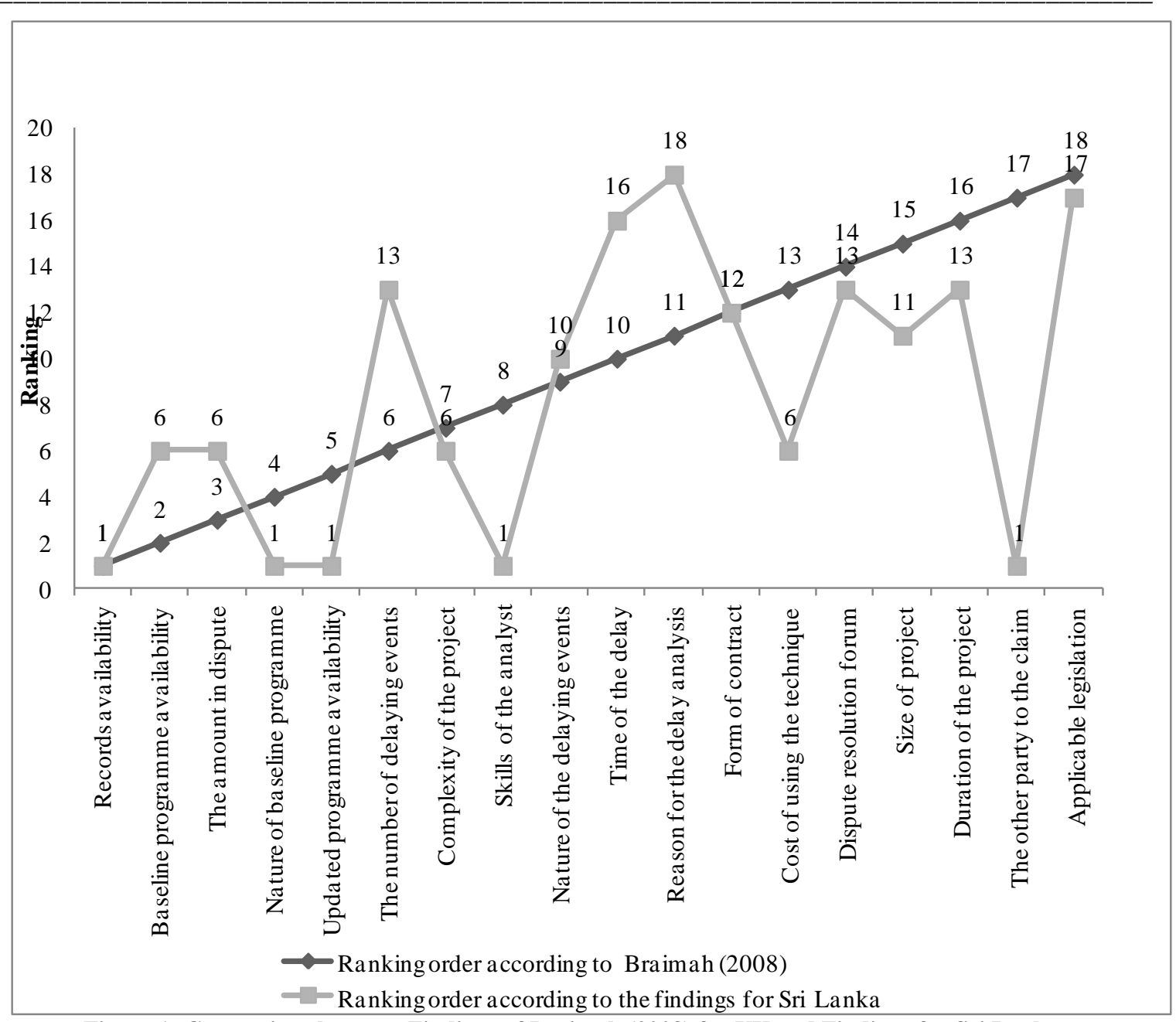

Figure 1: Comparison between Findings of Braimah (2008) for UK and Findings for Sri Lanka

\subsection{Identification of Utility Factors for the Sri Lankan Construction Industry}

Based on the data collected through part I of the questionnaire survey, the utility factors identified by the respondents were ranked using the RII formula. The utility factors were ranked as per their level of importance when considering the selection of a suitable DAT for a particular scenario. Table 5 reports the identified utility factors. The Table also presents the ranking of each identified utility factor based on its importance during the selection of DAT.

Based on the results derived from Table 5, "Record Availability", which carries a relative importance of $88.7 \%$, is the most important utility factor that needs to be considered when selecting a suitable DAT. Only if sufficient records are available does the affected party have the right to submit a claim for the delay; similarly, only if records are available would the analyst be able to make a veritable delay analysis for the particular scenario by selecting a suitable DAT.

Factors such as "Skills of the Analyst and Familiarity with the Project", "Nature of Baseline Programme", "Other Party to the Claim" and "Cost of Using the Technique" obtained more than $75 \%$ of the relative importance of consideration during the selection of a suitable DAT for a particular scenario. The other utility factors obtained less than $50 \%$ of relative importance.

Utility factors which obtained more than $75 \%$ of relative importance were considered for the AHP questionnaire. Table 5 presents them with the top 5 shaded. 


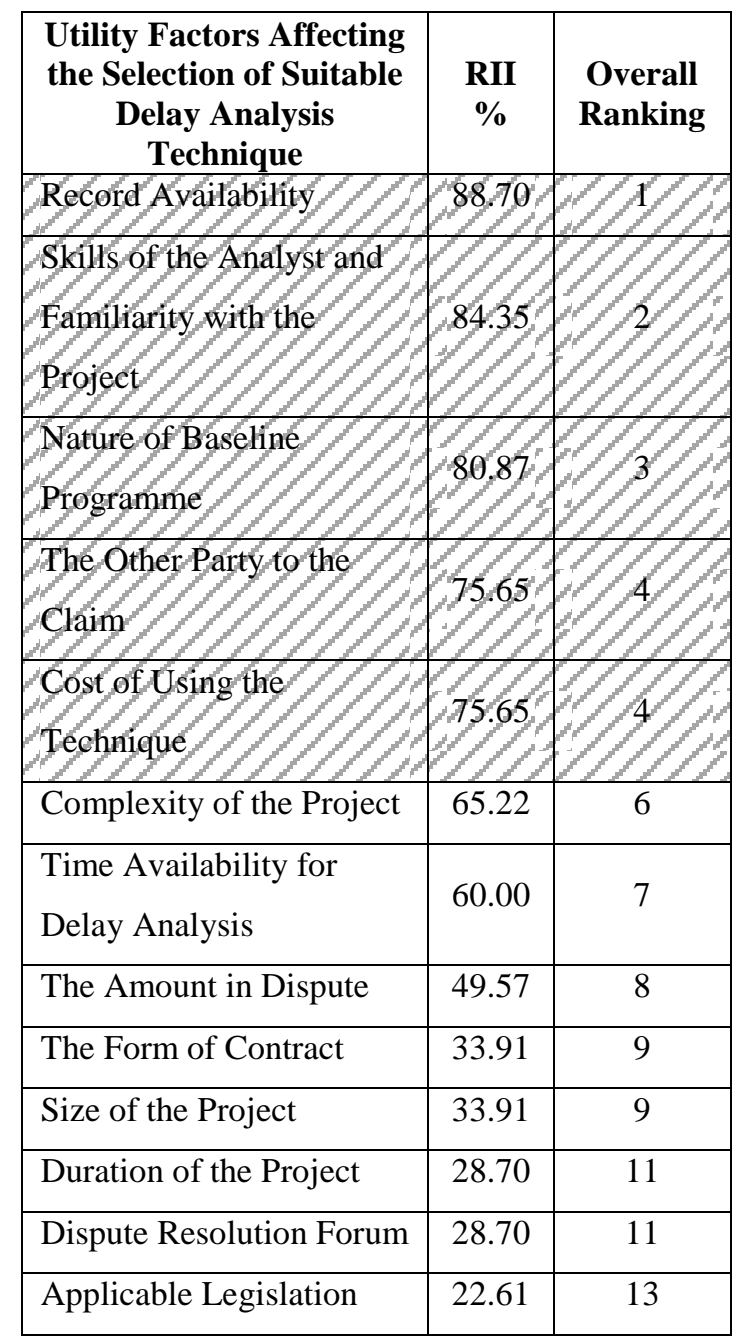

Most Important Utility Factor

Table 5: Utility Factors Affecting the Selection of DAT

\section{Conceptual Framework for Analysis of Delay in particular Scenario in the Sri Lankan Construction Industry}

Through the findings of part I of the questionnaire survey with experts, a conceptual model to analyse delay in a particular scenario was developed. The model takes into account all four main phases of a scenario: Identification of the delay type; Identification of filter factors; Selection of DAT by considering utility factors; and Analysis of the delay. Figure 2 presents this model. Prior to deciding on the DAT to be used, the analyst should identify the type of delay that has occurred, which would enable the analyst to filter out certain techniques depending on the context, a first step prior to taking a decision with regard to the utility factors. After screening out certain techniques from the filter factors (as shown in Figure 2 in the yes/no situation), the selection of one of the best methods from the rest depends upon the scoring or weightings of DATs and utility factors. If the analyst goes through the process specified, it will result in a solution that is satisfactory to all parties concerned. 


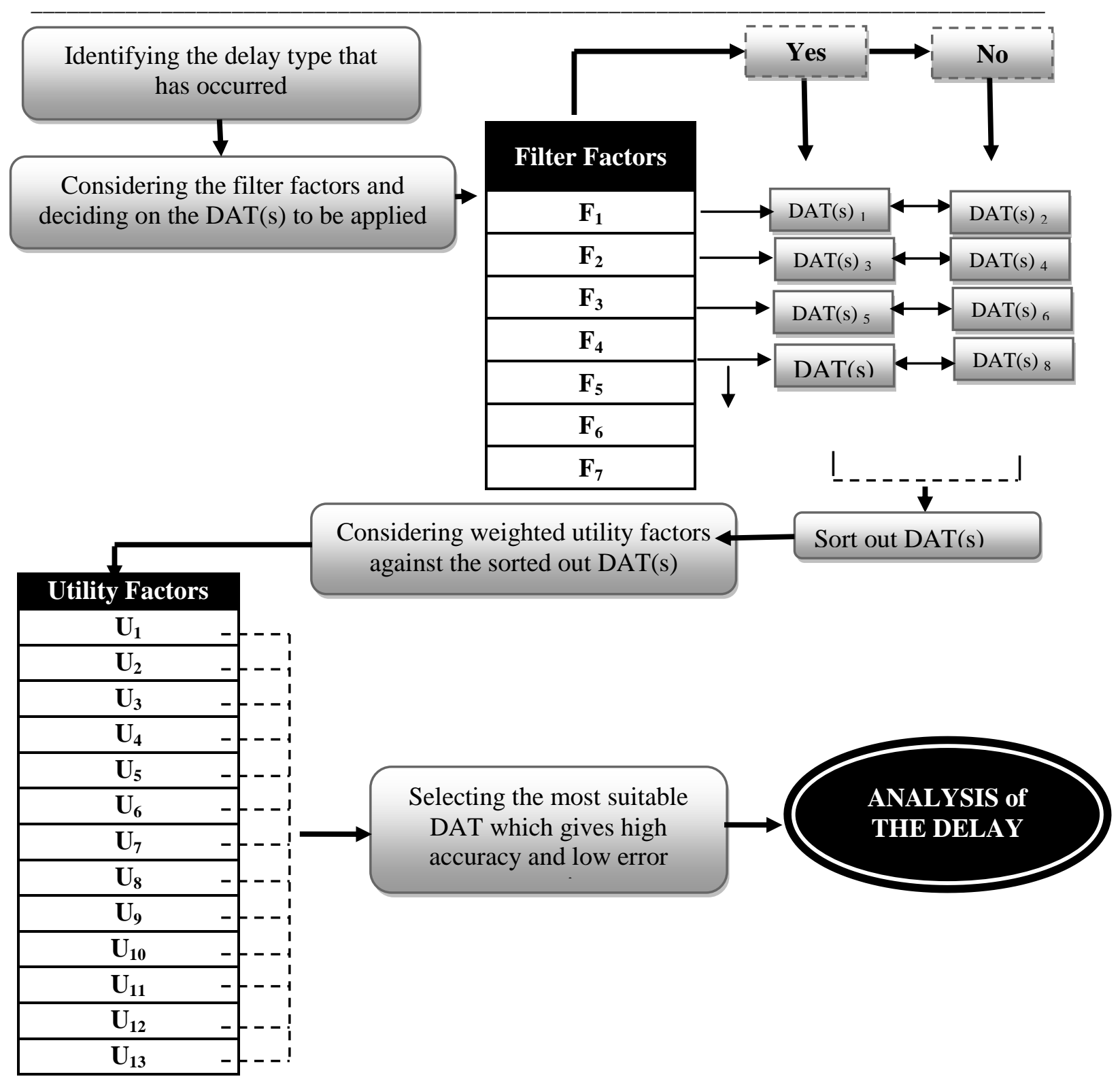

Figure 2: Conceptual Framework for Analysis of Delay Source: Sudeha, Perera \& Illankoon (2013) 


\section{Framework to Select the Most Suitable DAT by Considering Utility Factors for Particular Scenario in the Sri Lankan Building Construction Industry}

\subsection{Identification of the Most Important Utility Factors to Select Delay Analysis Technique}

As the first step in developing the framework, the level of importance of the utility factors for the purpose of selecting the delay analysis technique for a particular scenario was identified using the AHP tool. Three steps of calculation were adopted after the data obtained through part II of the questionnaire survey. In accordance with the AHP process, a pair-wise comparison, normalize calculation and consistency calculation were under taken to identify the most important utility factors when selecting DAT for the Sri Lankan building construction industry.

The results of the analysis are presented in Table 6. According to Ehrhardt and Tullar (2008), a utility factor with a higher importance score is preferred to one with a lower importance score. Among the five utility factors which were short-listed on the basis of results from part I of the questionnaire survey, the higher importance score of 0.511 (or $51.1 \%$ ) was held by "Record Availability", which underscores its status as the most important utility factor to be considered when selecting DAT for a particular scenario. "Skills of the Analyst and Familiarity with the Project" occupies second place in terms of the level of importance with a 0.264 (or 26.4\%) importance score. The third place in terms of level of importance was obtained by "Other Party to the Claim" with a 0.081 (or $8.1 \%$ ) importance score. "Nature of Baseline Programme" is a close fourth in terms of importance when selecting DAT with a 0.076 (or 7.6\%) importance score. The "Cost of Using the Technique" occupies fifth place in terms of level of importance with a 0.068 (or 6.8\%) importance score.

\begin{tabular}{|c|l|c|c|c|}
\hline \multicolumn{2}{|c|}{ Utility Factor } & $\begin{array}{l}\text { Importa } \\
\text { nce } \\
\text { Score }\end{array}$ & $\begin{array}{l}\text { Import } \\
\text { ance } \\
\%\end{array}$ & Rank \\
\hline A & $\begin{array}{l}\text { Record } \\
\text { Availability }\end{array}$ & 0.511 & 51.1 & 1 \\
\hline B & $\begin{array}{l}\text { Skills of the } \\
\text { Analyst and } \\
\text { Familiarity } \\
\text { with the } \\
\text { Project }\end{array}$ & 0.264 & 26.4 & 2 \\
\hline C & $\begin{array}{l}\text { Other Party } \\
\text { to the Claim }\end{array}$ & 0.081 & 8.1 & 3 \\
\hline D & $\begin{array}{l}\text { Nature of } \\
\text { Baseline } \\
\text { Programme }\end{array}$ & 0.076 & 7.6 & 4 \\
\hline E & $\begin{array}{l}\text { Cost of } \\
\text { Using the } \\
\text { Technique }\end{array}$ & 0.068 & 6.8 & 5 \\
\hline
\end{tabular}

Table 6: Ranking the Utility Factors in terms of Level of Importance

7.2 The Identification of the Level of Suitability of Delay Analysis Techniques in Considering Each Utility Factor

As the next step in developing the framework, the level of suitability of delay analysis techniques has been identified taking into consideration each utility factor by analyzing the data collected using the AHP tool. Table 7 brings together all the results in one table where the Relative Importance (RI) Score represents the score that each DAT has obtained and represents the level of suitability of each DAT when considering each utility factor. Further, according to Table 7 , the final importance score represents the suitability of DAT together with the utility factor in the overall delay analysis process. The final importance percentage demonstrates the same final important score in a manner that facilitates reader comprehension. 
Framework to Select the Most Suitable Delay Analysis Technique for Building Construction through a Consideration of Utility Factors

\begin{tabular}{|c|c|c|c|c|c|}
\hline $\begin{array}{l}\text { Utility } \\
\text { Factor }\end{array}$ & Delay Analysis Technique & RI Score & RI \% & $\begin{array}{c}\text { Final } \\
\text { Importance } \\
\text { Score }\end{array}$ & $\begin{array}{c}\text { Final } \\
\text { Importance } \\
\%\end{array}$ \\
\hline \multirow{5}{*}{$\begin{array}{c}\text { Record } \\
\text { Availability }\end{array}$} & Time Impact Technique & 0.362 & $36 \%$ & 0.185 & $18 \%$ \\
\hline & Collapsed as-built & 0.330 & $33 \%$ & 0.169 & $17 \%$ \\
\hline & As Planned vs As Built & 0.176 & $18 \%$ & 0.090 & $9 \%$ \\
\hline & Impact As-planned & 0.087 & $9 \%$ & 0.044 & $4 \%$ \\
\hline & Global Impact & 0.045 & $4 \%$ & 0.023 & $2 \%$ \\
\hline \multirow{5}{*}{$\begin{array}{l}\text { Skills of } \\
\text { the Analyst } \\
\text { and } \\
\text { Familiarity } \\
\text { with the } \\
\text { Project }\end{array}$} & Time Impact Technique & 0.358 & $36 \%$ & 0.095 & $9 \%$ \\
\hline & Collapsed As-built & 0.251 & $25 \%$ & 0.066 & $7 \%$ \\
\hline & As Planned vs As Built & 0.243 & $24 \%$ & 0.064 & $6 \%$ \\
\hline & Impact As-planned & 0.082 & $8 \%$ & 0.022 & $2 \%$ \\
\hline & Global Impact & 0.066 & $7 \%$ & 0.018 & $2 \%$ \\
\hline \multirow{5}{*}{$\begin{array}{c}\text { Other Party } \\
\text { to the } \\
\text { Claim }\end{array}$} & Global Impact & 0.416 & $42 \%$ & 0.034 & $3 \%$ \\
\hline & Impact As-planned & 0.253 & $25 \%$ & 0.021 & $2 \%$ \\
\hline & As Planned vs As Built & 0.191 & $19 \%$ & 0.015 & $2 \%$ \\
\hline & Time Impact Technique & 0.087 & $9 \%$ & 0.007 & $1 \%$ \\
\hline & Collapsed As-built & 0.053 & $5 \%$ & 0.004 & $0 \%$ \\
\hline \multirow{5}{*}{$\begin{array}{l}\text { Nature of } \\
\text { Baseline } \\
\text { Programme }\end{array}$} & As Planned vs As Built & 0.454 & $45 \%$ & 0.034 & $3 \%$ \\
\hline & Impact As-planned & 0.254 & $25 \%$ & 0.019 & $2 \%$ \\
\hline & Time Impact Technique & 0.132 & $13 \%$ & 0.010 & $1 \%$ \\
\hline & Collapsed As-built & 0.088 & $9 \%$ & 0.007 & $1 \%$ \\
\hline & Global Impact & 0.072 & $7 \%$ & 0.005 & $1 \%$ \\
\hline \multirow{5}{*}{$\begin{array}{l}\text { Cost of } \\
\text { Using the } \\
\text { Technique }\end{array}$} & Global Impact & 0.453 & $45 \%$ & 0.031 & $3 \%$ \\
\hline & Impact As-planned & 0.250 & $25 \%$ & 0.017 & $2 \%$ \\
\hline & As Planned vs As Built & 0.176 & $18 \%$ & 0.012 & $1 \%$ \\
\hline & Time Impact Technique & 0.081 & $8 \%$ & 0.005 & $1 \%$ \\
\hline & Collapsed As-built & 0.041 & $4 \%$ & 0.003 & $0 \%$ \\
\hline
\end{tabular}

Table 7: Level of Suitability of DATs When Considering Utility Factors 


\subsection{Level of Suitability of Each Delay Analysis Technique in Considering Utility Factors as a Whole in Analyzing Delays}

The previous sub-section (Section 7.2) discussed the level of suitability of each DAT in considering each utility factor. This section explains the level of suitability of each DAT taking into consideration the utility factors as a whole in analyzing delays. Suitability of each DAT is arrived at by adding the final importance score of each DAT which comes under each utility factor. The final importance score of each DAT which comes under each utility factor was calculated by multiplying the relative importance score of the particular utility factor and the relative importance score of each DAT under the particular utility factor. Table 8 presents the results of this analysis.

\begin{tabular}{|l|c|c|}
\hline $\begin{array}{c}\text { Delay } \\
\text { Analyzing } \\
\text { Technique }\end{array}$ & $\begin{array}{c}\text { Total Final } \\
\text { Importance } \\
\text { Score }\end{array}$ & $\begin{array}{c}\text { Overall } \\
\text { Ranking }\end{array}$ \\
\hline $\begin{array}{l}\text { Time Impact } \\
\text { Technique }\end{array}$ & 0.302 & 1 \\
\hline $\begin{array}{l}\text { Collapsed } \\
\text { As-built }\end{array}$ & 0.249 & 2 \\
\hline $\begin{array}{l}\text { As Planned } \\
\text { vs As Built }\end{array}$ & 0.215 & 3 \\
\hline $\begin{array}{l}\text { Impact As- } \\
\text { planned }\end{array}$ & 0.123 & 4 \\
\hline $\begin{array}{l}\text { Global } \\
\text { Impact }\end{array}$ & 0.111 & 5 \\
\hline
\end{tabular}

Table 8: Results of the Analysis of Level of Suitability of DATs Taking into Consideration Utility Factors as a whole

The results included in the Table give the rankings, as per the recommendation of the experts, with regard to the suitability of the DATs for analyzing delays when the whole utility factors are taken into consideration. According to the results, the "Time Impact Technique", which obtained a total final importance score of 0.302 ,earned the rank of one. Furthermore, with regard to analyzing delay in terms of utility factors, the "Time Impact Technique" gives more accurate results than the other four DATs. Occupying the second and third place rankings was "Collapsed As-built" and "As-planned vs. As-built" techniques respectively with total final scores of 0.249 and 0.215 which are only slightly lower than that for "Time Impact Technique."The fourth and fifth ranks were occupied by "Impact Asplanned" and "Global Impact Technique" respectively with 0.123 and 0.111 total final importance scores respectively. When compared with the top three techniques, "Impact As-planned" and "Global Impact" techniques show drastic differences with regard to scores. On the whole, the findings of the study demonstrate that the "Time Impact" technique gives the most accurate results with the least error margin for analysis of delay taking into consideration utility factors while the "Global Impact Technique" displays the least suitability.

\subsection{Development of a framework to Select the Most Suitable Delay Analysis Technique for the Sri Lankan Building Construction Industry Considering Utility Factors}

Since the aim of this research is to develop a framework to select the most suitable DAT for a particular scenario taking into consideration utility factors, it adopted the data analysis approach explained above. In accordance with the conceptual framework illustrated in Figure2,the analyst has to sort out DATs by considering filter factors to analyse the scenario. This section explains how a framework was developed to select the most suitable DAT among the sorted out DATs via the use of filter factors.

\begin{tabular}{|l|c|l|l|}
\hline $\begin{array}{c}\text { Delay } \\
\text { Analyzing } \\
\text { Technique }\end{array}$ & Coding & \multicolumn{1}{|c|}{$\begin{array}{c}\text { Utility } \\
\text { Factors }\end{array}$} & Coding \\
\hline $\begin{array}{l}\text { Time Impact } \\
\text { Technique }\end{array}$ & TI & $\begin{array}{l}\text { Record } \\
\text { Availability }\end{array}$ & A \\
\hline $\begin{array}{l}\text { Collapsed As- } \\
\text { built }\end{array}$ & CAB & $\begin{array}{l}\text { Skills of the } \\
\text { Analyst and } \\
\text { Familiarity } \\
\text { with the } \\
\text { Project }\end{array}$ & B \\
\hline $\begin{array}{l}\text { As Planned } \\
\text { vs. As-built }\end{array}$ & APAB & $\begin{array}{l}\text { Other Party to } \\
\text { the Claim }\end{array}$ & C \\
\hline $\begin{array}{l}\text { Impact As- } \\
\text { planned }\end{array}$ & IAP & $\begin{array}{l}\text { Nature of } \\
\text { Baseline } \\
\text { Programme }\end{array}$ & D \\
\hline Global Impact & GI & $\begin{array}{l}\text { Cost of Using } \\
\text { the Technique }\end{array}$ & E \\
\hline
\end{tabular}

Table 9: Coding System for Delay Analysis

Techniques and Utility Factors 


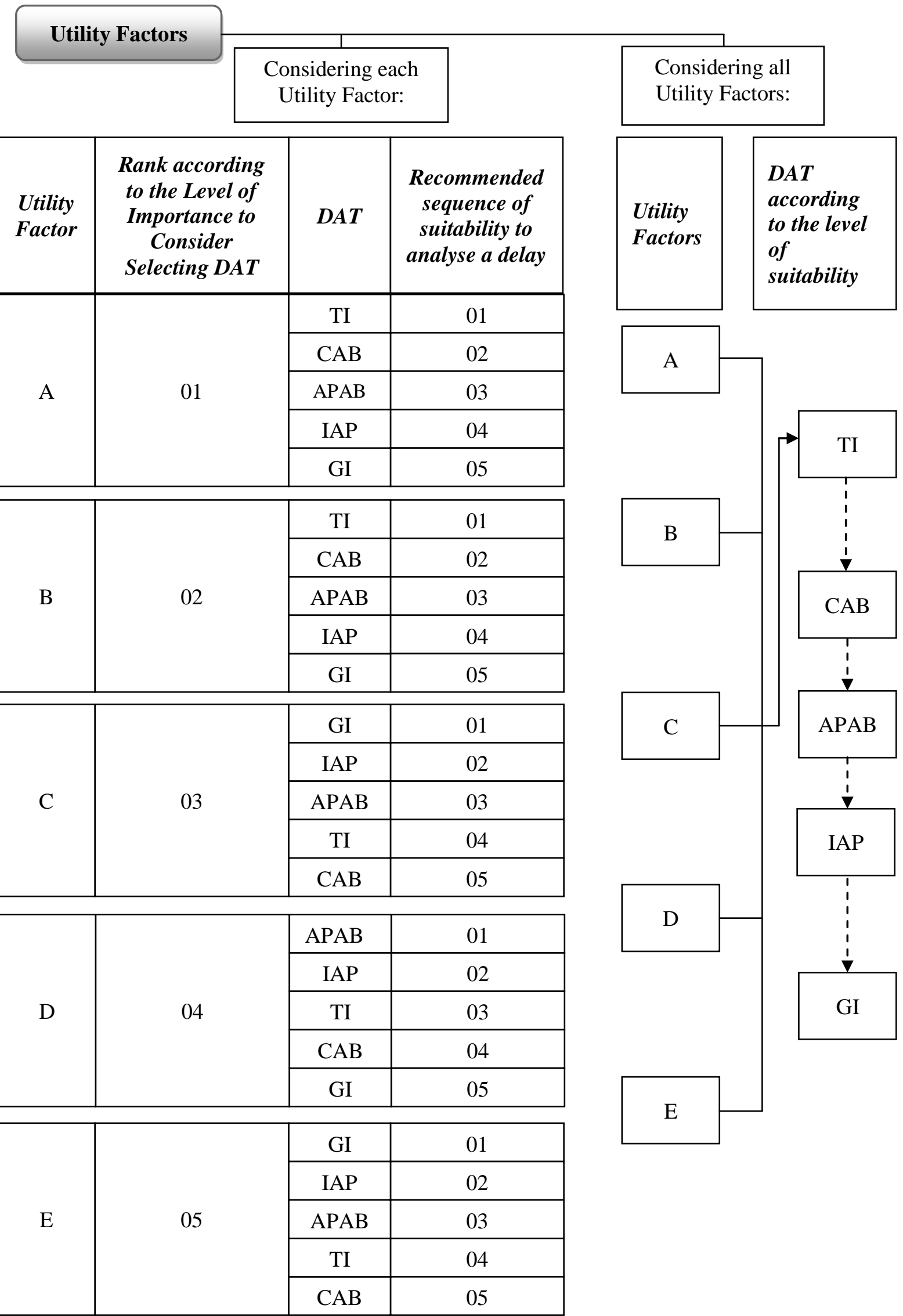

Figure 3: Framework to select the most suitable DAT to analyse a delay by considering utility factors 


\subsubsection{Use of Framework}

According to the developed framework, the analyst has two options for the purpose of selecting a DAT for a particular scenario taking into consideration utility factors. According to Figure 3, the analyst can select a DAT for a particular scenario by either considering one particular utility factor or all the utility factors. Before going through this process, the analyst however has to sort out suitable DATs using filter factors. After sorting out suitable DATs for a particular scenario, the next step is to select the most suitable DAT among the selected DATs by considering utility factors. At that stage, the framework which is developed in Figure 3 can be used.

Of the two options described above, if the analyst selects the most suitable DAT by considering only one utility factor, that procedure is demonstrated under the "consider one utility factor" heading. The framework gives each utility factor and ranks each factor in terms of its importance in being considered when selecting the DAT. Next, the DATs are given and ranked in terms of the level of suitability to analyse the delay when considering the utility factor. For example, if the analyst only considers "Record Availability" (Utility Factor A) to select the DAT to analyse the particular scenario, the best technique to select the method of analysis is the TI method. Furthermore, in order to select one utility factor, the utmost priority has to be given to factor A, which is shown at the top of the format. This gives the least priority to factor E. After selecting the suitable utility factor, consideration has been given to DAT. The best option with regard to utility factor $\mathrm{A}$ is considered as TI. The list has been arranged in descending order in terms of order of priority. Hence, GI carries less importance in terms of utility factor A. But, in option one, where the analyst selects one utility factor, the effect or the accuracy of the final result will not change even if the analyst goes for different utility factors since it is quite enough that consideration has been given more to the best DAT.
When consideration has been given to all the utility factors, what matters is not the best utility factor but the best DAT. Since the framework gives the best option as TI, the suitable DAT are again shown in a descending order where the least priority is given to the option GI.

\section{Conclusions}

Construction delays are very common in the construction industry. To analyse and to arrive at a fair decision in the case of the parties implicated in the delay analysis process, it should be comprehensive. In the Sri Lankan construction industry, most delay analysts appear to adopt ad-hoc methods in selecting DAT to analyse delay. Such an approach increases the error margin and reduces the accuracy of the analysis. An increase in the error margin of a particular analysis ultimately results in an inaccurate outcome which has an adverse impact on the delay analysis process. Taking these problems into consideration, a framework has been developed that emphasizes the benefits of selecting the most suitable DAT to analyse a particular scenario and undertaking a systematic analyzing process. The proposed framework helps to reduce the error margin while increasing the accuracy of the analysis, which carries benefits for both parties. The framework highlights several aspects to selecting DAT for a particular scenario: identification of the criticality of utility factors; identification of the suitability of DATs in analyzing delay by considering each utility factor separately and together; and the current usage level of DATs. It thus helps delay analysts to select the most suitable DAT for a particular scenario by considering utility factors.

\section{Recommendations}

The proposed conceptual framework (see Figure 2) and developed framework (see Figure 3) form the basis of the recommendation to select a DAT for a particular scenario by considering utility factors and for the analysis of delay in the Sri Lankan building construction industry. It is therefore recommended to adopt the framework in selecting the most suitable 
DAT to analyse delays in building projects, either organization-wise or project-wise. It will ultimately result in a more accurate result with a lower error margin.

It is further recommended that professionals who work in the Sri Lankan construction industry enhance their knowledge of delay types and available processes for analyzing delay. In addition, professionals who are in the business of analyzing delays should possess greater knowledge about the various delay analysis methods available and ways to use them to analyse delay.

\section{REFERENCES}

Alkass, S., Mazerolle, M., \& Harris, F. (1996). Construction Delay Analysis Techniques. Construction Management and Economics, 14, 375-394.doi:10.1080/014461996373250

Alkass, S., Mazerolle, M., Tribaldos, E., \& Harris, F. (1995). Computer Aided Construction Delay Analysis and Claims Preparation. Journal of Construction Management and Economics, 13, 335-352. Retrieved from http://www.tandfonline.com/doi/abs/10.1080/014461995000000

Arditi, D., \& Pattanakitchamroon, T. (2006). Selecting a Delay Analysis Method in Resolving Construction Claims. International Journal of Project Management, 24(2), 145-155. Retrieved from http://www.sciencedirect.com/science/article/pii/S0263786305000906

Braimah, N. (2008). An Investigation into the Use of Construction Delay and Disruption Analysis Methodologies. Master's thesis, University of Wolverhampton. Retrieved from http://core.kmi.open.ac.uk/download/pdf/1932701

Braimah, N., \& Ndekugri, I. (2008). Factors Influencing the Selection of Delay Analysis Methodologies. International Journal of Project Management, 26(8), 789-799. doi:10.1016/j.ijproman.2007.09.001

Chehayeb, N. N., Dozzi, P.S., \& AbouRizk, S. (1995). Apportioning Delay Method: Is There Only One Solution? In Proceedings of Construction Congress, (pp. 217-224). Retrieved from http://cedb.asce.org/cgi/WWWdisplay.cgi?96875

Cheng, E.W.L., \& Li, H. (2001). Information Priority-setting for Better Resource Allocation using Analytic Hierarchy Process. Information Management and Computer Security, 9(2), 6170.doi:10.1108/09685220110388827

Day, P.K. (2002). Project Risk Management: A Combined Analytic Hierarchy Process and Decision Tree Approach. Cost Engineering, 44(3), 13-26. Retrieved from http://yunus.hun.edu.tr/ aulucan/pdf/projectrisk.pdf

Ehrhardt R., \& Tuller, W.L. (2008). Rating Recruiting Sources at Simtec Instruments Corporation: Applying Multiple-criterion Decision Making in an HR Setting, Journal of human resources education, 2(1), 1-11. Retrieved from http://business.troy.edu/jhre/

El-Sayegh, S.M. (2008). Risk Assessment and Allocation in the UAE Construction Industry. International Journal of Project Management, 26(1), 431-438. Retrieved from http://www.journals.elsevier.com/international-journal-of-project-management/

Enshassi, A., Al-Najjar, Y., \& Kumaraswamy, M. (2009). Delays and Cost Overruns in the Construction Projects in the Gaza Strip. Journal of Financial Management of Property and Construction, 14(2), 126-151.doi:10.1108/13664380910977592 
Gunarathne, Y.M.S.B. (2012). Factors Affecting for Selection of Suitable Delay Analysis Technique for Sri Lankan Construction Industry. (Unpublished undergraduate dissertation. University of Moratuwa, Sri Lanka.

Hegazy, T., \& Zhang, K. (2005). Daily Window Delay Analysis. Journal of Construction Engineering and Management, 131(5), 505-512. Retrieved from http://dx.doi.org/10.1061/(ASCE)07339364(2005)131:5(505).

Institute of Dispute Management Professionals. (2013). Dispute Management. Retrieved from http://www.idmp.lk/

Jeyamathan, J., \& Rameezdeen, R. (2006). Skills and Competencies of Quantity Surveyors: the Case of Sri Lanka. In Rameezdeen, R. \& Senevirathne, I., Customizing the Quantity Surveyor to face the Challenges in Year 2020 (pp. 9 -18). Moratuwa: Department of Building Economics.

Kraiem, Z. M., \& Diekmann, J. E. (1987). Concurrent Delays in Construction Projects. Journal of Construction Engineering and Management, 113(4), 591-602. Retrieved from http://wlv.openrepository.com/wlv/bitstream/2436/38824/3/Braimah_PhD\%20thesis.pdf

Lam, K., \& Zhao, X. (1998). An Application of Quality Function Development to Improve the Quality to Teaching. International Journal of Quality and Reliability Management, 15(4), 389413.doi:10.1108/02656719810196351

Leary, C. P., \& Bramble, B. B. (1988). Project Delay: Schedule Analysis Models and Techniques. In Proceeding of Symposium on Project Management, (pp. 63-69). Retrieved from http://ascelibrary.org/doi/abs/10.1061/\%28ASCE\%29CO.1943-7862.0000096

Lee, D. M. (1983). Time Impact Analysis-forensic Scheduling. In Proceeding of Conference of Liability in Construction Management, (pp. 43-55). Retrieved from http://cedb.asce.org/cgi/WWWdisplay.cgi?38949

Lovejoy, V. A. (2004). Claims Schedule Development and Analysis: Collapsed as-built Scheduling for Beginners. Journal of Cost Engineering, 46(1), 27-30. Retrieved from http://connection.ebscohost.com/c/articles/12173898/claims-schedule-development-analysiscollapsed-as-built-scheduling-beginners

Lucas, D. E. (2002). Schedule Analyser Pro - an Aid in the Analysis of Delay Time Impact Analysis. Journal of Cost Engineering, 44(8), 30-36. Retrieved from http://www.citeulike.org/user/mpektas/article/7282063

Lyons, T., \& Skitmore, M. (2004). Project Risk Management in the Queensland Engineering Construction Industry. International Journal of Project Management, 22(1), 5161.doi:10.1016/S0263-7863(03)00005-X

Menesi, W. (2007). Construction Delay Analysis under Multiple Baseline Updates. Master's thesis, University of Waterloo, Canada. Retrieved from http://www.scribd.com/doc/59763547/

Pinnell, S. (1998). How to get paid for Construction Changes: Preparation, Resolution Tools and Techniques [Adobe Digital Editions version]. Retrieved from http://www.abebooks.com/servlet/BookPL?bi=9859054001\&3D9780070502291\%26sortby\%3 D13 
Ramanathan, C., Narayanan, S.P., \& Idrus, A.B. (2012). Construction delays causing risks on time and cost - a critical review. Australasian Journal of Construction Economics and Building, $12 \quad$ (1) 37-57. Retrieved from http://epress.lib.uts.edu.au/journals/ index.php/AJCEB/article/viewFile/2330/2811

Reams, J. M. (1989). Delay analysis: A systematic approach. Journal of Cost Engineering, 31(2), 12-16. Retrieved from http://www.researchgate.net/publication/35476822_ Delay_analysis_:A_systematic_approach_ev=sim_pub

Rubin, R. A., Fairweather, V., \& Guy, S. D. (3rd Ed.). (1999). Construction Claims: Prevention and Resolution [Adobe Digital Editions version]. Retrieved from www.extension.ait.ac.th/news/sem24sept/SEMINAR_AGENDA.pdf

Semple, C., Harman, T.T., \& Jergeas, G. 1994. Construction claims and disputes: Causes and cost/time overruns. Journal of Construction Engineering and Management, 120(4), 785795.doi:10.1061/(ASCE)0733-9364(1994)120:4(785)

Shi, J., Cheung, S., \& Arditi, D. (2001). Construction Delay Computation Method. Journal of Construction Engineering and Management, 127 (1), 60-65.doi:10.1061/(ASCE)07339364(2001)127:1(60)

Society of Construction Law.(2002). Delay and Disruption Protocol. Retrieved from http://www.scl.org.uk/resources.

Stumpf, G. R. (2000). Schedule delay analysis. Journal of Cost Engineering, 42(7), 32-43. Retrieved from http://cat.inist.fr/?aModele=afficheN\&cpsidt=15148342

Sumithiran, Y. (2009). A Mature Profession of Quantity Surveying in Sri Lanka. Unpublished undergraduate dissertation.University of Moratuwa, Sri Lanka.

Sudeha, H.M.C.K., Perera, B.A.K.S., \& Illankoon, I.M.C.S. (2013). Utility factors affecting for selecting delay analysis technique. In Proceedings of the Second World Construction Symposium, (pp. 473-482).

Wickwire, J. M., \& Groff, M. J. (2004). Update on CPM proof of delay claims and schedule update. Journal of Project Management Scheduling, 1(3), 3-9. Retrieved from http://heinonline.org/HOL/LandingPage?collection=journals\&handle=hein.journals/pubclj18\& $\operatorname{div}=22 \&$ id $=\&$ page $=$

Wickwire, J. M., Driscoll, T. J., \& Hurlbut, S. B. (1991).Construction scheduling: Preparation, liability, and claim [Adobe Digital Editions version]. Retrieved from http://www.aspenpublishers.com/HighLights/newhifi/H07355299492007-C.pdf

Yang, J. B., Kao, C.K., \& Lee, Y.Y. (2006). System requirement analysis of a construction delay analysis system. In Proceeding of $23^{\text {rd }}$ International Symposium on Automation and Robotics in Construction, (pp.02-106).Retrieved from http://www.iaarc.org/publications/ fulltext/isarc200600019_200606010050 .pdf

Yang, J.B., \& Kao, C.K. (2009). Review of Delay Analysis Methods: A Process-based comparison. Journal of the Open Construction and Building Technology, 3, 81-89. Retrieved from http://www.benthamscience.com/open/tobctj/articles/V003/81TOBCTJ.pdf 